\title{
Methodology to quantify clogging coefficients for grated inlets. Application to SANT MARTI catchment (Barcelona)
}

\author{
M. Gómez ${ }^{1} \mid$ J. Parés ${ }^{1}$ | B. Russo ${ }^{2}$ | E. Martínez-Gomariz ${ }^{1}$ (]
}

${ }^{1}$ Flumen Research Institute, Technical University of Catalonia, Barcelona, Spain

${ }^{2}$ Group of Hydraulic and Environmental

Engineering, Technical School of La Almunia

(EUPLA), University of Zaragoza, La Almunia

de Doña Godina, Zaragoza, Spain

Correspondence

Eduardo Martínez-Gomariz, Flumen Research

Institute, Technical University of Catalonia,

Barcelona, Spain.

Email: eduardo.martinez@cetaqua.com
Within the drainage system of a city, the set of inlets is in charge of taking the runoff produced by local storms to the stormwater/sewer. In the drainage system design the selection of appropriate inlet models and their location is one of the fundamental aspects. The hydraulics of these inlets has received great attention within the last years; however, few inlet makers provide the hydraulic capacity of their products. In addition, these data usually consider clean water, while in reality, numerous inlets can be either totally or partially clogged. This aspect should be kept in mind within the design process. In this paper, a methodology to consider the hydraulic effects of clogging phenomena is presented. The work started from a visual inspection of the grated inlets throughout the urban catchment of Sant Martí, Barcelona, as a means of identifying clogging patterns, their repetitive forms and their associated frequency. After that, clogged patterns were reproduced in laboratory testing of typical inlets types, thereby obtaining the real quantity of water that could be captured by each of them. It was shown that the same expression employed to describe the efficiency of clean inlets can be used to assess the efficiency of those clogged. A reduction factor in terms of hydraulic capacity and related to each clogging pattern has been defined for use in hydraulic studies of runoff along streets. Finally, the paper compares the obtained results in terms of clogging coefficient with another experimental campaign carried out in other catchment of the city.

\section{KEYWORDS}

catchment, clogging, inlet, surface water

\section{1 | INTRODUCTION}

Streets constitute a surface hydraulic network during rain events when runoff flows along the streets. Flow on the streets in a rainy day depends on several factors like rainfall intensity, urban area, slopes, street cross-sections, and finally the type and number of inlets. Streets have an important role associated to stormwater management and any street must ensure safety for pedestrians (Gómez, Macchione, \& Russo, 2011; Martínez, Gómez, \& Russo, 2016; Russo et al., 2013a) and vehicular traffic according to a level of service associated to a return period (Martínez, Gómez, Russo, \& Djordjevíc, 2017, 2018).
Drainage system can be seen as composed by two subsystems: the underground with stormwater/sewer sections and the surface one, formed by streets. This concept of dual drainage system is the best description of what really occurs during a rain event. But these two sub-systems are not independent. They are connected by the so-called inlets system composed by all the inlets, grates, gullies, etc. placed in the city aiming to capture the runoff. At the same time, in case of pressure stormwater/sewer flow, they behave as a relief valve, by allowing the excess of water not accepted by the stormwater/sewer conduit to emerge to the street level. Hundreds or thousands of inlets are responsible to link both systems whose primary function is to take the runoff to the 
stormwater/sewers up to the right place [Artina et al., 2001; Colorado Department of Transportation (CDOT), 2000] and onward for treatment.

Nowadays, a large variety of inlets and grates exist in the market, different from countries and even from cities, where local adaptation to streets design and meteorological conditions has produced such different shapes, dimensions and, as a consequence, different models. Many times, aesthetic concepts influence inlet design as in many other disciplines, though unfortunately several cities decide the inlet selection putting first these "new" criteria with no consideration of their hydraulic capacity or the problems associated to their normal operation with clogging. Moreover, in several countries it is possible to find that most of local suppliers provide no data concerning the hydraulic efficiency of their products. Although several procedures like HEC-22 provide information about how to assess the water collected, they are restricted to some inlet shapes that are not found all over the world (Brown, Stein, \& Warner, 1996).

Recent studies propose some procedures to characterise inlet hydraulic performance. Most of times they are based on real-scale experimental analysis and, as a result, allow the estimation of captured flow depending on street geometry, inlet type, and gutter flow conditions [Clark County Regional Flood Control District (CCRFCD), 1999; Gómez \& Russo, 2011; Russo et al., 2013b]. In these studies, laboratory tests are usually done in best conditions (i.e., clean water, inlet with no clogged area, no obstacles, etc.) so, the obtained results expressed in terms of inlet hydraulic efficiency can be considered as an upper limit that can be unrealistic in case of inlet clogging. In fact, in real conditions, dust, dirt, leaves, or debris, can reduce the area of grated inlet holes, thereby reducing the amount of water to be captured. In order to take into account the clogging phenomenon, Guo (2006) proposed the concept of clogging coefficient, which reduces the hydraulic efficiency with a factor between 0 and 1 (Guo, 2006), although the proposed values were not related to theoretical or experimental studies. Clogging phenomenon depends on inlet design, type and density of vegetation, rainfall patterns, street slope, cleaning frequency, etc. Although the reproduction of the effects of this phenomenon is complex, laboratory and field studies could allow a reasonable estimation of the potential reduction in terms of hydraulic efficiency due to clogging.

So inlets testing under various clogging conditions should be required, being characterisation of clogging behaviour and its severity an important pre-requisite for a correct design of surface drainage systems. However, it might be wondered whether finding a characteristic way of the inlet to be clogged is possible. In previous studies, Gómez, Hidalgo, and Russo (2013) introduced this idea through the "clogging pattern" concept where, depending on the type of inlet, some characteristic forms where holes are covered by leaves, debris, etc. were observed. The study was developed in an urban catchment of Barcelona (Riera Blanca) including steep and flat slopes. However, one doubt could appear: are those clogging patterns representative of the whole city? In order to answer this question, the authors of this work selected another catchment in Barcelona with different characteristics, closer to the beaches, flat slopes, and potentially more prone to be affected by clogging, and maybe to develop different patterns.

As stated before, clogging effects are specific of local climate conditions, land use, street geometry, and inlet models. The methodology developed could be applied with no loss of generality anywhere though. In this work, the following features were considered:

- Field visits in dry and wet weather conditions, to observe throughout the catchment before and after rain events the way inlets become clogged.

- Comparison of the clogged inlets to identify common aspects in order to define clogging patterns, and assess the frequency associated to each one.

- Quantification of the reduction of hydraulic capacity associated to each one of the clogging patterns, through experimental studies carried out in the hydraulic laboratory of the Technical University of Catalonia (following UPC laboratory).

- Proposal of clogging coefficients at the end of the process, to be used for each pattern, and make it extensive to other case studies.

\section{I STORMWATER CAPTURED BY INLETS}

An excess of water over the pavement can generate safety problems for pedestrians and vehicles. Sometimes it is responsible of accidents due to aquaplaning (i.e., loss of adherence between tires and pavement) and loss of stability for pedestrians and vehicles. Many cities have initiated studies oriented to quantify the street hydraulics and procedures to determine best location for inlets.

Hydraulic capacity of a single inlet depends on different parameters: street geometry, street flow, and type of inlet (Gómez \& Russo, 2011; Russo et al., 2013b). The flow captured by an inlet could be high or low in general, although it depends essentially on the comparison with the street flow. Absolute flow captured by the inlet sometimes is not enough to have a clear idea of the hydraulic performance of an inlet. That is why the concept of hydraulic efficiency $(E)$ is defined as the ratio between the captured flow $\left(Q_{\mathrm{c}}\right)$ over the flow along the street and approaching the inlet $(Q)$. This parameter provides more objective information about the performance of a single inlet respect to the street flow. Efficiency $(E)$ ranges from 0 to 1 and it is a dimensionless parameter. 


$$
E=\frac{Q_{c}}{Q}
$$

As previously stated, tests for achieving inlet hydraulic efficiency are usually conducted under the best conditions with clear water and no debris. Reality within a city is not like this, no matter the efforts from the municipal cleaning services. Although intense street washing and sweeping is carried out, a certain layer of dust and other debris-like leaves from trees will be built up. During a rain event, the urban runoff, the most effective cleaning process in a city, sweeps away most of these debris and once the inlet is reached water enters into the stormwater/sewer and debris covers partially or totally the inlet. That is why in the urban street design, a kind of security coefficient reducing the efficiency should be considered.

In order to assess the coefficients to affect the hydraulic efficiency of the inlets, a field study in an urban catchment of the city of Barcelona was developed. Visual inspections and pictures of every selected inlet were collected (Figure 1). A comprehensive analysis of the clogged inlets was carried out, by determining several types of clogging patterns, their associated frequency and their spatial distribution. Once the field study was finished, a quantification of the efficiency reduction was determined through laboratory tests, and reduction coefficients of hydraulic efficiency were proposed.

\section{3 | TEST CASE: SANT MARTI CATCHMENT IN BARCELONA}

The urban catchment in the district of Sant Marti in Barcelona, with an area of $6.49 \mathrm{~km}^{2}$ was selected as test case to implement the methodology (Figure 2). The catchment is located in the lower part of the city, next to the Mediterranean Sea with elevation from 1 to $18 \mathrm{~m}$. The reasons (Parés, 2014) to select this catchment are:

- Most of the catchment is located on reclaimed land, initially below sea level. Gravels and sand deposits are the usual geology in the area. Due to this, flat morphology is the normal profile with slopes from 0.1 to $5 \%$ and an average of $0.5 \%$, thus the inlets are more prone to be clogged. Beaches are close to the area so sands carried by the wind can be found all over the area of interest.
- Available Geographic Information System (GIS) information including position and type of every inlet located in the catchment (Figure 2). This information was provided by former CLABSA, now BCASA, the public company in charge of the management of the city sewer system.

- The inlet system is composed by 6,946 inlets, with 6,874 inlets that can be grouped in 98 different models, while 72 are non-classified models. Moreover seven models are enough to describe $80 \%$ of all the inlets.

For all these reasons, Sant Martí catchment could be seen as an example for the worst case regarding inlets clogging, due to its morphological climatic conditions (Mediterranean climate characterised by short and intense rainfalls).

The first part of the study included the direct visual inspection to verify the database of inlets, according to GIS information, classified by the Universal Transverse Mercator (UTM) coordinates and inlet type. According to the existing types within the database, seven models were selected as the most representative ones. These models are E5, R-121, Impu, Meridiana, Delta/Barcelona, Teide and Onda/Ebro and, as previously mentioned, they represent $80 \%$ of all the inlets in the catchment. In Table 1 inlet distribution for every model is shown.

From the 5,539 inlets, a group of 1,300 inlets was selected. The selection criteria were a uniform spatial distribution of the inlets along the catchment and a minimum of $15 \%$ of every model. One of the objectives is to check whether the clogging patterns are uniformly distributed along the catchment or not.

Each of the 1,300 inlets was visually inspected, three times as a minimum, and a picture of each one was taken to record the real condition of the inlet. In order to take into account the potential effect of soil erosion due to rainfall in the clogging phenomenon, two wet field observations were planned. These two visits were conducted within the days after a rain event (1-3 maximum) during the rainy season in Barcelona (autumn), while the last third visit was carried out under dry weather conditions (in spring), with a minimum of 2 weeks with no rainfall, to check if the clogging patterns are modified by the activity of the municipal cleaning services. (a)

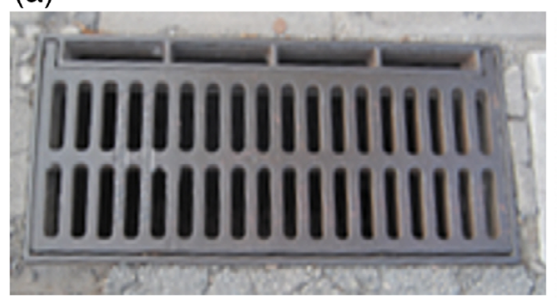

(b)

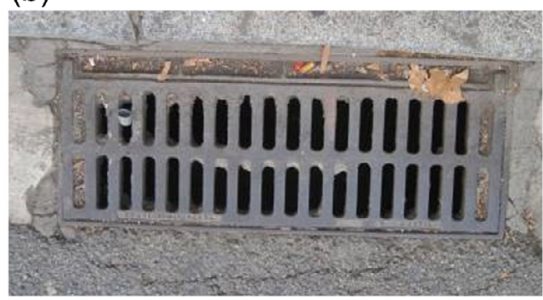

(c)

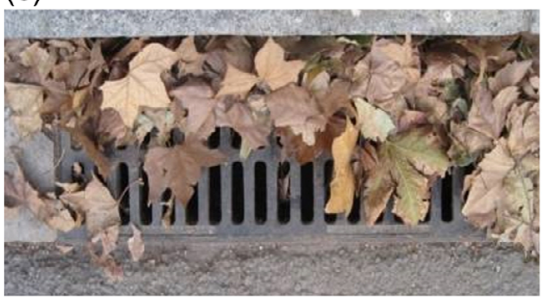




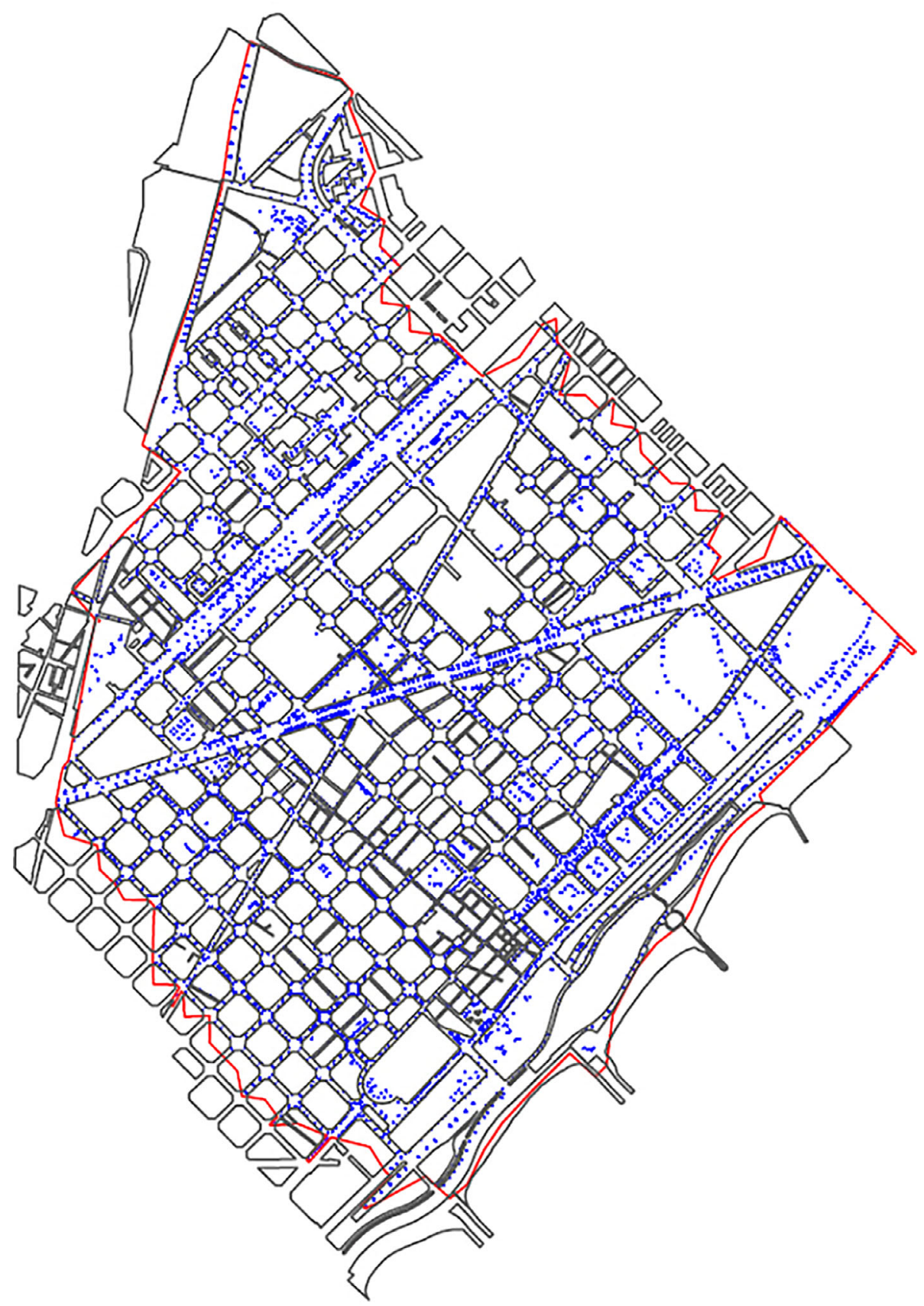

FIGURE 2 General view of the basin and inlets. Inlets are indicated with dots

TABLE 1 Number of the selected inlet models in the catchment

\begin{tabular}{|lll|}
\hline Inlet model & Total & \% of inlets in the basin \\
\hline Inlet no. 1: E5 & 257 & 3.70 \\
\hline Inlet no. 2: R-121 & 425 & 6.12 \\
\hline Inlet no. 3: IMPU & 616 & 8.87 \\
\hline Inlet no. 4: Meridiana & 1,162 & 16.73 \\
\hline Inlet no. 5: Delta/Barcelona & 2,226 & 32.05 \\
\hline Inlet no. 6: Teide & 233 & 3.35 \\
\hline Inlet no. 7: Onda/Ebro & 620 & 8.93 \\
\hline Total & 5,539 & 79.74 \\
\hline Total St. Martí catchment & 6,946 & 100 \\
\hline
\end{tabular}

\section{4 | CLOGgING PATtERNS}

At the end of the fieldwork, an extensive graphical data set was performed and employed for the analysis of the inlets. Due to the small differences, clogging states under dry and wet weather conditions were combined to simplify the approach. The analysis was undertaken straightly in the PC screen, not considering yet computer vision processes that could be employed to accelerate the process. However, the percentage of holes covered by leaves or debris (i.e., clogging elements) is possible to be distinguished as a general value. The criteria indicated in the Table 2 were adopted. Due to these criteria, specific clogging patterns 
TABLE 2 Proposed criteria to classify clogging patterns following the field inspection

\begin{tabular}{ll} 
Nothing (clean inlet) & $\boldsymbol{A}_{\mathbf{c}} / \boldsymbol{A}_{\mathbf{h}}<\mathbf{1 0} \%$ \\
\hline Pattern C1 & $10 \% \leq A_{\mathrm{c}} / A_{\mathrm{h}}<25 \%$ \\
\hline Pattern C2 & $25 \% \leq A_{\mathrm{c}} / A_{\mathrm{h}}<50 \%$ \\
\hline Pattern C3 & $50 \% \leq A_{\mathrm{c}} / A_{\mathrm{h}}<80 \%$ \\
\hline Inlet out of order & $A_{\mathrm{c}} / A_{\mathrm{h}} \geq 80 \%$ \\
\hline
\end{tabular}

were defined depending on the ratio between the clogged area $\left(A_{\mathrm{c}}\right)$ and the total area of holes in the inlet $\left(A_{\mathrm{h}}\right)$.

For two different inlets of same model and clogged area, likely the clogging does not always have the same shape. To simplify the approach, some clogging shapes related to every pattern have been proposed (i.e., describing the most general manner the inlet is clogged), according to the fieldwork observations. Shapes associated to the different clogging patterns were more easily recognised for some inlets (i.e., Ebro, Teide, or IMPU), while for other inlets (E5 and 4 Meridiana) few or no clogging problems were observed, thus no patterns were proposed for those inlets. Clogging pattern $\mathrm{C} 1$ is associated to the coverage of narrow spaces, many times next to the external perimeter of the inlet. Some of the inlets show a more intense clogging effect, in case that cleaning process is not enough, thus a $\mathrm{C} 2$ pattern is proposed. Differences between $\mathrm{C} 1$ and $\mathrm{C} 2$ patterns are more intense for inlets 3, 5, 6, and 7 (i.e., IMPU, Barcelona, Teide, and Ebro).

Finally, if the clogging process progresses, another pattern, called C3, can be observed, where a significant area of holes is covered. It was observed that not all the inlets reach C3 pattern, while inlets 1, 2, and 4 (E5, R-121, and Meridiana) are then less susceptible to develop this pattern. In Figure 3 the proposed shapes for every clogging pattern of the selected seven inlet models are presented.

The inlets with higher susceptibility to be clogged are inlets Ebro, Teide, and IMPU, maybe due that they are old models, placed around 30 years ago. Inlets E5, Meridiana, and Barcelona have been installed more recently, within the last 5-10 years, and show to have better conditions to avoid clogging effects. This difference could be explained by poor maintenance or inadequate cleaning of these grated inlets.

\section{I FREQUENCIES AND DISTRIBUTION OF CLOGGING PARTNERS}

Frequencies and spatial distribution of clogging patterns were assessed under dry and wet weather conditions. Frequency distribution can be considered quite similar for both situations, hence the related values in all cases were combined and only a single frequency was presented. Therefore, it was observed that clogging phenomenon occurs throughout the year in wet and rainy season, and it seems that patterns do not depend on temporality.
Second relevant aspect is that after viewing the spatial distribution of clogging patterns, those appear all over the catchment. No significant differences between higher or lower slope areas were observed, thus it may indicate that according to the observed data, clogging patterns show a quite uniform spatial distribution throughout the catchment. Those differences could be responsible for the time needed to move from one pattern to another. This aspect has not been verified though.

The more common patterns are $\mathrm{C} 1$ and $\mathrm{C} 2$, with frequencies between 20 and $70 \%$, while pattern $\mathrm{C} 3$ is less frequent, with frequencies from 2 to $9 \%$. The frequency of patterns $\mathrm{C} 1$ and $\mathrm{C} 2$ is approximately the same for all the inlets, except for inlet Ebro, where $\mathrm{C} 1$ pattern is more usual $(75 \%)$ than C2 (15\%).

In addition, an interesting issue is to compare the number of inlets that show some clogging problem. This could be expressed by combining the frequencies associated to $\mathrm{C} 1$, $\mathrm{C} 2$, and $\mathrm{C} 3$ patterns. The accumulated frequency $(\mathrm{C} 1+\mathrm{C} 2+\mathrm{C} 2)$ is approximately $95 \%$ for Ebro, $89 \%$ for Teide, $60 \%$ for IMPU, 38\% for R-121, 10\% for Barcelona, and $0 \%$ for Meridiana and E5 (Table 3).

\section{I HYDRAULIC ANALYSIS OF CLEAN AND CLOGGED INLETS}

So far, a description of the clogging problems in the Barcelona's catchment of Sant Martí has been presented. Notwithstanding, one of the objectives of this work is the quantification of the reduction of the hydraulic efficiency due to clogging problems within inlets.

In previous studies developed at the UPC (Technical University of Catalonia - BarcelonaTech) (Gómez \& Russo, 2011; Martínez, 2000), it was proposed that hydraulic inlet efficiency $(E)$ can be related to the approach flow $(Q)$ and the immediately upstream water level $(y)$ as a potential function as follows:

$$
E=A \cdot\left(\frac{Q}{y}\right)^{-B}
$$

where $E$ is hydraulic efficiency for the inlet, $Q$ is approaching flow to the inlet $(1 / \mathrm{s}), y$ is water level immediately upstream the inlet (mm), A and B are two specific coefficients for every inlet.

This expression was proposed after conducting laboratory tests with clean water and no clogging effects. Thus, the issue to be solved is whether this expression is still valid for clogged inlets, or another approach or formula is needed to describe the hydraulic efficiency of a clogged inlet.

Two inlets of the seven selected ones were tested in the UPC laboratory, and it was proved that the same potential function proposed for clean waters could be used for clogged inlets, just modifying the A and B coefficients depending on the clogged area. 


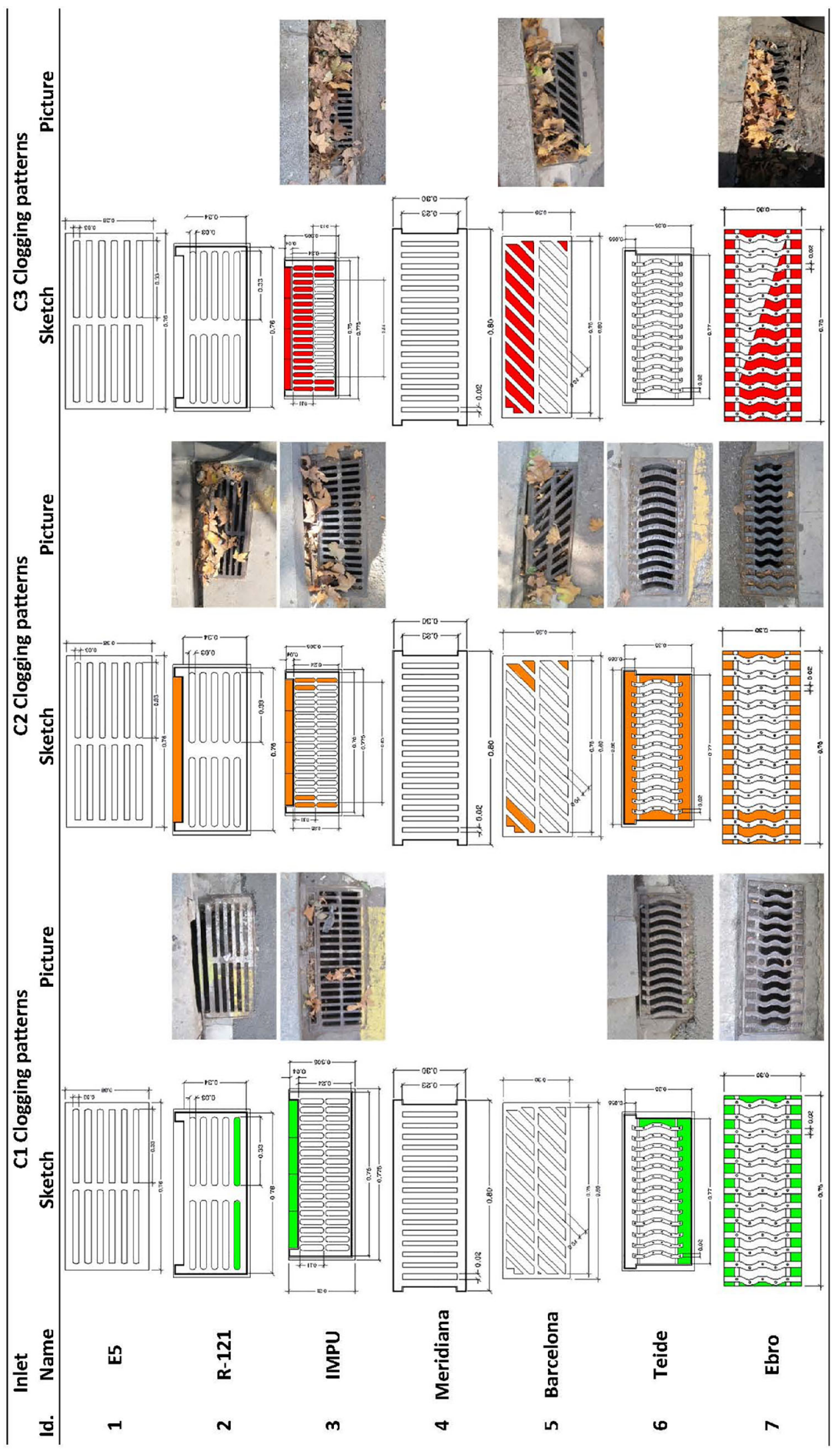


TABLE 3 Frequencies associated to each one of the observed clogging patterns

\begin{tabular}{|c|c|c|c|c|c|c|}
\hline Inlet model & Pattern C1 (\%) & Pattern C2 (\%) & Pattern C3 (\%) & Pattern $\mathrm{C} 1+\mathrm{C} 2+\mathrm{C} 3(\%)$ & Out of order (\%) & Total $(\%)$ \\
\hline E5 & 0.00 & 0.00 & 0.00 & 0.00 & 0.00 & 0.00 \\
\hline $\mathrm{R}-121$ & 18.37 & 17.35 & 0.00 & 37.76 & 3.06 & 40.82 \\
\hline IMPU & 22.37 & 18.42 & 9.21 & 60.53 & 1.32 & 61.84 \\
\hline Meridiana & 0.00 & 0.00 & 0.00 & 0.00 & 1.50 & 1.50 \\
\hline Barcelona & 0.00 & 7.48 & 2.55 & 10.04 & 0.73 & 10.77 \\
\hline Teide & 40.00 & 49.09 & 0.00 & 89.09 & 0.00 & 89.09 \\
\hline Ebro & 75.54 & 15.11 & 4.32 & 94.97 & 1.44 & 96.41 \\
\hline
\end{tabular}

The same test protocol used for clean water conditions was adopted (Gómez \& Russo, 2011), with circulating flows of $25,50,100,150$, and $200 \mathrm{~L} / \mathrm{s}$, longitudinal slopes of $0,0.5,1,2,4,6,8$, and $10 \%$ and transverse slopes of 0,1 , 2,3 , and $4 \%$.

Tests were developed by covering with gypsum part of the holes of the inlet, reproducing the pattern to be studied, as can be seen in Figure 4 for Barcelona inlet. Experimental data are presented in Figure 5, and from the analysis of these results it is possible to conclude that a potential law is good enough to represent the hydraulic capacity of the clogged inlets. Parameters A and B have varied according to clogged area (Table 4), although quite high correlation coefficients were obtained for the two inlets [i.e., 91.5\% for Barcelona inlet (Pattern C3), 77.2\% for Teide inlet (Pattern C1), and 75.9\% for Teide inlet (Pattern C2)]. This confirms the applicability of the verified potential law for clean inlets to clogged inlets too.

\section{I COEFFICIENTS A AND B FROM GEOMETRICAL CHARACTERISTICS OF THE INLET}

Parameters A and B can be determined from experimental tests as stated before. But in many cases engineering departments of local municipalities have no time or possibilities to test the grates they are planning to place. Gómez and Russo (2011) presented a proposal to approximate the A and B parameters from the inlet geometry, in case the non-tested grate has similar dimensions to those of the tested inlets. The expressions to estimate $\mathrm{A}$ and $\mathrm{B}$ are:

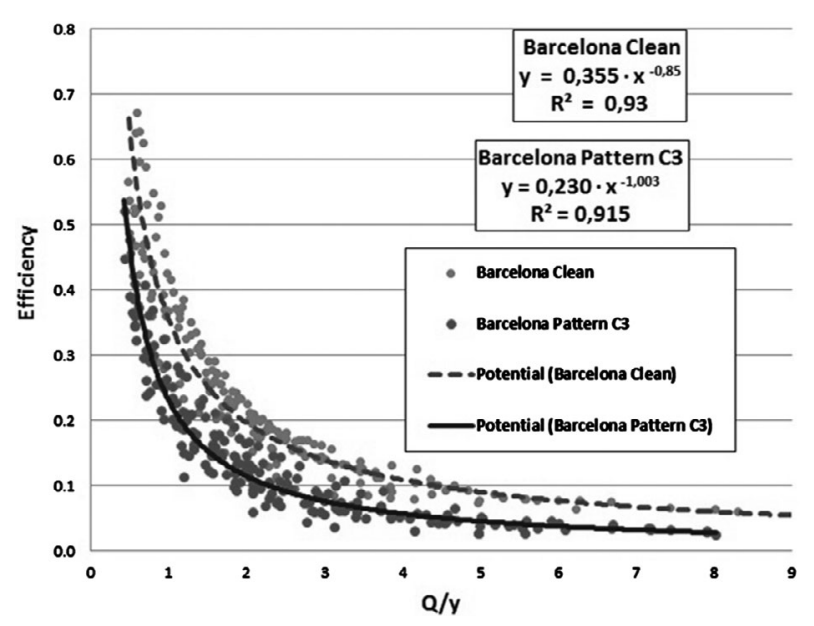

FIGURE 5 Barcelona inlet. Clean water and C3 conditions

TABLE 4 Parameters a, B determined after laboratory tests

\begin{tabular}{lllll} 
Teide & Inlet clean & Pattern C1 & Pattern C2 & Pattern C3 \\
A & 0.425 & 0.340 & 0.327 & - \\
B & 0.714 & 0.800 & 0.790 & - \\
Barcelona & Inlet clean & Pattern C1 & Pattern C2 & Pattern C3 \\
A & 0.355 & - & - & 0.230 \\
B & 0.850 & - & - & 1.003 \\
\hline
\end{tabular}

$$
\begin{gathered}
A=\frac{1.988 \cdot A_{g}{ }^{0.403}}{p^{0.19} \cdot\left(n_{t}+1\right)^{0.088} \cdot\left(n_{l}+1\right)^{0.012} \cdot\left(n_{d}+1\right)^{0.082}} \\
B=1.346 \cdot \frac{L^{0.179}}{W^{0.394}}
\end{gathered}
$$

where $A_{g}$ is minimum rectangular area in the inlet including all the holes $\left(\mathrm{m}^{2}\right), \mathrm{p}$ is ratio in \% between the total area of
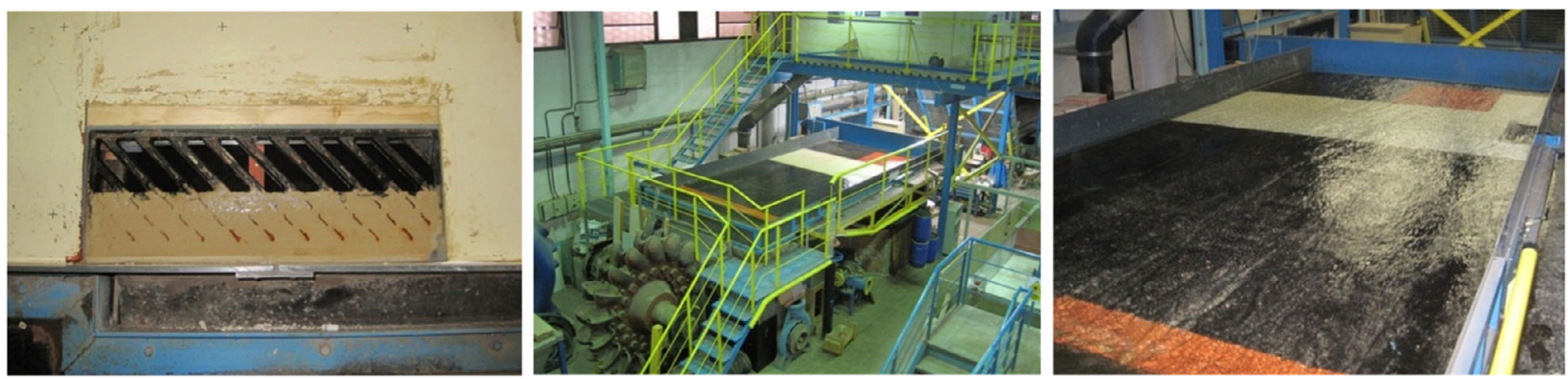

FIGURE 4 Reproduction of C3 clogging pattern for the Barcelona inlet, and views of the experimental set-up 
holes $A_{\mathrm{H}}$ and the $A_{\mathrm{g}}$, defined as $\mathrm{p}=\left(\mathrm{A}_{\mathrm{H}} / \mathrm{A}_{\mathrm{g}}\right) \cdot 100, \mathrm{n}_{\mathrm{t}}$ is number of transversal bars of the inlet, $n_{1}$ is number of longitudinal bars of the inlet, $n_{\mathrm{d}}$ is number of diagonal bars of the inlet, $L$ is length of the inlet $(\mathrm{cm}), W$ is width of the inlet $(\mathrm{cm})$.

These expressions can be employed to clean inlets, while it was not clear whether this expression is applicable to clogged inlets. For the selected and tested clogged inlets, the relevant geometrical information (total area of available holes, number of bars, etc.) was obtained and A and B values were calculated with expressions 3.1 and 3.2. These values were compared with the obtained $\mathrm{A}$ and $\mathrm{B}$ from the tests, as Table 5 indicates.

Values show very similar results, with differences in the second decimal position. This could indicate that for nontested inlets it is possible to approximate the A and B parameters with Equations 3.1 and 3.2, and, as a consequence, it is possible to quantify the reduction of hydraulic efficiency on the inlet due to the clogging effects. Naturally, the experimental procedure is preferred, though in case of not having the possibility to carry out laboratory tests, it is possible to calculate the A and B parameters of clogged inlets to estimate their hydraulic efficiency reduction.

\section{I PROPOSAL OF CLOGGING COEFFICIENTS}

As stated before, users consider most of times a security coefficient, reducing hydraulic efficiency of the inlet, in order to consider the clogging effects. However, according to most references, it is usually a fixed value of 0.5 (Gómez et al., 2013), thus reducing efficiency to half of the value found in laboratory test with clean water conditions. In this work, it was observed that not all the inlets show the same clogging pattern, and frequencies of occurrence of clogging are not the same for all types of inlets. Therefore, depending on the clogging pattern, if a reduction of $50 \%$ of hydraulic efficiency is applied, real hydraulic capacity of the inlet could be underestimated or overestimated.

It is accepted that efficiency reduction can be expressed as:

$$
E_{\text {clogged }}=\left(1-c_{o}\right) \cdot E_{\text {clean }}
$$

TABLE 5 A and B parameters obtained from experimental tests and from inlet geometry

\begin{tabular}{|c|c|c|c|}
\hline \multirow[b]{2}{*}{ Parameter } & \multicolumn{2}{|l|}{ Inlet Teide } & \multirow{2}{*}{$\begin{array}{l}\text { Inlet Barcelona } \\
\text { C3 pattern }\end{array}$} \\
\hline & C1 pattern & C2 pattern & \\
\hline A experimental & 0.340 & 0.327 & 0.230 \\
\hline A from geom & 0.365 & 0.311 & 0.265 \\
\hline B experimental & 0.800 & 0.790 & 1.003 \\
\hline B from geom & 0.777 & 0.790 & 1.022 \\
\hline
\end{tabular}

where $E_{\text {clogged }}$ is efficiency of the clogged inlet, $E_{\text {clean }}$ is efficiency of the clean inlet, and $c_{\mathrm{o}}$ is clogging coefficient, from 0 to 1 ( 0 clean inlet, 1 totally covered inlet).

If expression is rewritten by introducing the $\Delta E$ parameter, as the difference between $E_{\text {clean }}$ and $E_{\text {clogged }}$, the clogging coefficient co can be expressed as:

$$
\frac{\Delta E}{E}=\frac{E_{\text {clean }}-E_{\text {clogged }}}{E_{\text {clean }}}=c_{0}
$$

Nevertheless, as it was presented within the previous sections, efficiency of clean or clogged inlet can be approximated by a potential law, as a function of the $Q / y$ parameter, with varying values depending on both flow conditions and street geometry. It is possible to represent the efficiency reduction as a function of flow conditions $Q / y$. Figure 6 shows the evolution of $c_{o}$ against flow for the two tested inlets, and for each tested clogging pattern (i.e., $\mathrm{C} 1, \mathrm{C} 2$, and C3). It is possible to observe that clogging coefficient increases with the flow along the street, thus it is not constant, and values are different for every pattern.

Notwithstanding, the design criteria of drainage system are associated to a return period considered for the design storm employed for the calculations. Therefore, design values for $c_{\mathrm{o}}$ should not be related to low flow conditions, but to higher values of $Q$. On the other hand, in urban areas high hazard conditions for pedestrian and vehicles are mainly related to high flow velocities (and consequently medium and low flow depths $y$ ) produced by low roughness of impervious surfaces like streets and sidewalks and/or their high slope (Martínez et al., 2016, 2017, 2018; Russo et al., 2013a) In this framework, it seems justified the adoption of high ratios $Q / y$ for the design of surface drainage systems. If the ratio $Q / y=10$ is considered as a reference for high hazard conditions, coefficients for $c_{\mathrm{o}}$ are indicated in Table 6 , for the tested inlets and associated patterns.

Gómez et al. (2013), as a result of a very similar experience focused on another catchment of Barcelona (Riera

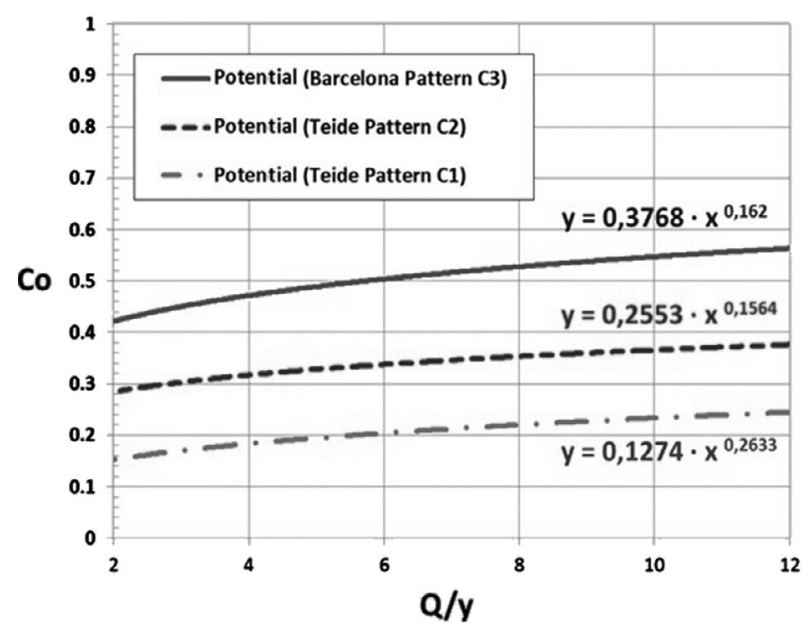

FIGURE 6 Evolution of clogging coefficients against flow conditions for tested inlets 
TABLE 6 Clogging coefficients for tested inlets considering $Q / y=10$

\begin{tabular}{llll}
$\boldsymbol{C}_{\mathbf{o}}=\boldsymbol{\Delta} \boldsymbol{E} / \boldsymbol{E}$ & Pattern C1 & Pattern C2 & Pattern C3 \\
Teide & 0.234 & 0.360 & - \\
Barcelona & - & - & 0.545 \\
\hline
\end{tabular}

Blanca), provided other values concerning clogging coefficient for other types of inlets. The definition of the patterns for both experiences was the same and, in order to compare the results obtained in the two experimental campaigns, the values presented in Table 7 are referred to the flow condition $Q / y=10$.

On the basis of the analysis of the results obtained in these two campaigns it is possible to state that, depending on the inlet and the clogging pattern observed, values of $c_{\mathrm{o}}$ can be close to the traditionally used value of 0.5 or not. Clogging coefficients for pattern $\mathrm{C} 1$ are closer to $0.25-0.50$, hence a performance of the collecting system is better than that considered by most users. On the other hand, for the most critical clogging pattern (C3), clogging factor is always higher than 0.5 reaching in some cases values closer to 0.7 . On the other hand, clogging coefficient is not the same for all the inlets. It was observed that some types are more prone to be clogged, and others show less clogging problems. Thus, when clogging coefficients are employed within the design of inlets systems, the type of inlet and the clogging patterns observed in the analysed catchment must be considered.

\section{9 | CONCLUSIONS}

In this paper, a methodology to consider the clogging issues of inlets placed along the streets has been proposed. Fieldwork observations in an urban catchment located in the city of Barcelona has been also carried out.

Every inlet type shows different clogging patterns, with a different frequency of occurrence in the catchment. Some inlet types are more prone to be affected by this issue and some others are less affected by clogging. This phenomenon could be related to the time the inlets have been placed on the streets. Inlets with more clogging problems, Ebro, IMPU, and Teide were placed 30 years ago, and inlets with fewer problems like E5, Meridiana, and Barcelona have been placed within last 5-10 years. This difference could be explained by poor maintenance or inadequate cleaning of the grated inlets.

Clogging patterns have been found all over the catchment, presenting a uniform spatial distribution. The slope of the street was not found to influence the clogging pattern;

TABLE 7 Clogging coefficients for tested inlets considering $Q / y=10$

$\begin{array}{llll}\boldsymbol{C}_{\mathbf{o}}=\boldsymbol{\Delta} \boldsymbol{E} / \boldsymbol{E} & \text { Pattern C1 } & \text { Pattern C2 } & \text { Pattern C3 } \\ \text { IMPU } & 0.451 & 0.502 & 0.674 \\ \text { EBRO } & 0.265 & 0.400 & 0.667\end{array}$

however, it could accelerate the clogging effect and the transfer from one pattern to another. This aspect should be addressed in future studies.

According to the observations, clogging patterns and frequency of occurrence were similar before and after rain events, under dry and wet weather conditions. In this case, this can be due to the efforts of municipal cleaning services.

Reduction of inlet efficiency is observed and the hydraulic characterisation of a clogged inlet can be undertaken by employing the same potential law proposed for clean inlets. A consequence of this fact is that specific parameters of this formula (i.e., A and B parameters) vary for the clogged inlet respect to the values for clean inlets. Parameters can be obtained from laboratory tests or can be approximated according to the geometry of the clogged inlet, by considering the same expressions employed for clean inlets but applying it to the clogged geometry (i.e., considering the effective hole area) of the inlets suffering clogging phenomena.

The clogging coefficient usually considered as 0.5 uniformly all over the catchment, can vary depending on the type of inlet, and the clogging pattern observed. The values of clogging coefficients obtained in this work have been compared to other values obtained during another experimental campaign carried out in another catchment of Barcelona (Riera Blanca). The results of both studies show that clogging coefficient $c_{\mathrm{o}}$ can be in the range of 0.23 to 0.50 for the most usual clogging patterns, while for the worst case, clogging factor should be closer to 0.7 .

In any case, every inlet for every pattern will have different $c_{\mathrm{o}}$ and these values should be employed to describe much better the reality of the collecting system within an urban area.

\section{ACKNOWLEDGEMENTS}

The authors acknowledge the cooperation of the company in charge of the sewer system management in Barcelona during the period of the field study, CLABSA, as well as the cooperation of BCASA, public company now in charge of Barcelona's sewer network.

\section{ORCID}

E. Martínez-Gomariz (iD https://orcid.org/0000-0002-0189-0725

\section{REFERENCES}

Artina, S., Calenda, G., Calomino, F., Cao, C., La Loggia, G., Modica, C., ... Veltri, P. (2001). Sistemi di fognature, Manuale di progettazione. Milano, Italy: Hoepli.

Brown, S. A., Stein, S. M. \& Warner, J. C. (1996). Urban drainage design manual (Hydraulic Engineering Circular No. 22). Washington, DC: Federal Highway Administration, US Department of Transportation.

Clark County Regional Flood Control District (CCRFCD). (1999). Hydrologic criteria and drainage design manual. Las Vegas, NV: Clark County Regional Flood Control District. 
Colorado Department of Transportation (CDOT). (2000). Hydraulic design criteria for highways. Hydraulic Division Center. Denver, CO: CDOT.

Gómez, M., Macchione, F., \& Russo, B. (2011). Methodologies to study the surface hydraulic behaviour of urban catchments during storm events. Water Science and Technology, 63(11), 2666-2673. https://doi.org/10.2166/wst.2011.174

Gómez, M., \& Russo, B. (2011). Methodology to estimate hydraulic efficiency of drain inlets. ICE Institution of Civil Engineers, Water Management, 164(2), 81-90.

Gómez, M., Hidalgo, G., \& Russo, B. (2013). Experimental campaign to determine grated inlet clogging factors in an urban catchment of Barcelona. Urban Water Journal, 10(1), 51-60. https://doi.org/10.1080/1573062X. 2012.690435

Guo, J. C. Y. (2006). Design of street curb opening inlets using a decay-based clogging factor. Journal of Hydraulic Engineering, 132(11), 1237-1241.

Martínez, E., Gómez, M., Russo, B., \& Djordjevíc, S. (2018). Stability criteria for flooded vehicles: A state-of-the-art review. Journal of Flood Risk Management, 11(S2), S817-S826. https://doi.org/10.1111/jfr3.12262

Martínez, E., Gómez, M., Russo, B., \& Djordjevíc, S. (2017). A new experiments-based methodology to define the stability threshold for any vehicle exposed to flooding. Urban Water Journal, 14(9), 930-939. https:// doi.org/10.1080/1573062X.2017.1301501

Martínez, E., Gómez, M., \& Russo, B. (2016). Experimental study of the stability of pedestrians exposed to urban pluvial flooding. Natural Hazard, 82(2), 1259-1278. https://doi.org/10.1007/s11069-016-2242-z
Martínez, P. (2000). Study of the efficiency of inlets and design criteria in urban areas (Minor thesis; in Spanish). School of Civil Engineering, U.P.C. Barcelona.

Parés, J. (2014). Study of the clogging patterns in the Sant Marti catchment in Barcelona (Minor thesis; in Spanish). School of Civil Engineering, U.P.C. Barcelona.

Russo, B., Gómez, M., \& Macchione, M. (2013a). Pedestrian hazard criteria for flooded urban areas. Natural Hazard, 69(1), 251-264. https://doi.org/10. 1007/s11069-013-0702-2

Russo, B., Gómez, M., \& Tellez, J. (2013b). Methodology to estimate the hydraulic efficiency of nontested continuous transverse grates. Journal of Irrigation and Drainage Engineering, 139(10), 864-871.

How to cite this article: Gómez $M$, Parés $J$, Russo B, Martínez-Gomariz E. Methodology to quantify clogging coefficients for grated inlets. Application to SANT MARTI catchment (Barcelona). J Flood Risk Management. 2019;12:e12479. https://doi.org/ $\underline{10.1111 / \mathrm{jfr} 3.12479}$ 